\title{
Reduction of Carbon Dioxide Emission in Thermal Power Plants by using Particle Swarm Optimization Technique
}

\author{
K.Senthil \\ Department of EEE \\ St.Joseph College of \\ Engineering \& Technology \\ Dar Es Salaam, Tanzania
}

\author{
K.Manikandan \\ Department of EEE \\ S.R.M University \\ Chennai, India
}

\author{
Ignatius A Herman \\ Department of CSE \\ St.Joseph College of \\ Engineering \& Technology \\ Dar Es Salaam, Tanzania
}

\author{
L.Saravanan \\ Department of ECE \\ St.Joseph College of \\ Engineering \& Technology \\ Dar Es Salaam, Tanzania
}

\begin{abstract}
Climate change as the greatest environmental challenge facing the world today. Power stations play a major role in greenhouse gas emissions. Nearly $21.3 \%$ of green house gases are emitted by power plants alone. The main sources of greenhouse gases are due to burning of fossil fuels and deforestation leading to higher carbon dioxide concentrations. Normally $\mathrm{CO}_{2}$ in the atmosphere is removed by mixing into the ocean $\&$ photosynthesis process but it takes long time. The proposed method reduces the carbon dioxide emission in gas power plants by using computational approach of particle swarm optimization technique. In this paper the Particle Swarm Optimization (PSO) solution to economic dispatch problem is very useful when addressing heavily constrained optimization problem in terms of solution accuracy. Results obtained from this technique clearly demonstrate that the algorithm is more efficient in terms of number of evolution to reach the global optimum point. It also shows that the solution method is practical and valid for real time applications. It solves the Economic Load Dispatch (ELD) power system problem using Particle Swarm Optimization algorithm for three generator system and six generator system with emission constraints. The algorithm was used to check the validity; quality of the solution and the results shows that emission values are very low compared with conventional methods.
\end{abstract}

\section{Keywords}

Climate Changes, carbon dioxide Emission, particle swarm optimization, thermal Power Plant, fossil fuels and deforestation.

\section{INTRODUCTION}

The physical and chemical reactions such as nitrogen $\left(\mathrm{N}_{2}\right)$, oxygen $\left(\mathrm{O}_{2}\right)$ and argon (Ar) are not greenhouse gases. This is because molecules containing two atoms of the same element such as $\mathrm{N}_{2}$ and $\mathrm{O}_{2}$ and monatomic molecules such as Ar have no net change in their dipole moment when they vibrate and hence are almost totally unaffected by infrared light. Although molecules containing two atoms of different elements such as carbon monoxide $(\mathrm{CO})$ or hydrogen chloride $(\mathrm{HCl})$ absorb IR, these molecules are short-lived in the atmosphere owing to their reactivity and solubility. As a consequence they do not contribute significantly to the greenhouse effect and are not often included when discussing greenhouse gases. In the industrial era, human activities have added greenhouse gases to the atmosphere, mainly through the burning of fossil fuels and deforestation. The seven sources of $\mathrm{CO}_{2}$ from fossil fuel combustion are Solid fuels $35 \%$, liquid fuels $36 \%$, gaseous fuels $20 \%$, flaring gas $<1 \%$, cement production $3 \%$, non-fuel hydrocarbons $<1 \%$, the "international bunkers" of shipping and air transport 4\%.Major sources of an individual's greenhouse gas include home heating, cooling, electricity consumption, and transportation.

The context of environmental policy, climate change usually refers to changes in modern climate. It may be qualified as anthropogenic climate change, more generally known as warming. Some parts of the climate system, such as the oceans and ice caps, respond slowly in reaction to climate forcing because of their large mass. Therefore, the climate system can take centuries or longer to fully respond to new external forcing. The sun is the predominant source for energy input to the Earth. Both long- and short-term variations in solar intensity are known to affect global climate. The anthropogenic factor is the reason for increase in $\mathrm{CO}_{2}$ levels due to emissions from fossil fuel combustion. Other factors such as land use, ozone depletion, animal agriculture and deforestation the affecting climate. Electricity generation produces $\sim 250 \mathrm{~g} / \mathrm{kWh}$, or 2,200 $\mathrm{mTCO}_{2}$ e per MW-year.

The traditional method of solving economic dispatch problems such as lambda-iteration and gradient method (Wood and Woollenberg, 1984) require the unit input-output curves of generators. However, these curves do not increase monotonically due to prohibited operating zones. Hence, the traditional dispatch algorithms cannot be directly used to optimize such non-linear cost function. The Hierarchical approach of Lagrange multiplier method [1] to find incremental fuel cost for subsystems comprising groups of units. The solution searches for optimal lamda for various choices of fuel and generation range of units iteratively. In this formulation multiple intersecting cost functions are assumed. This method has application to fossil generation units capable of burning gas and oil, as well as other problems which result in multiple intersecting cost curves for a particular unit. The results show that the solution method is practical and valid for real-time applications.

Dynamic Programming (DP) [2] method is to solve the nonconvex ED problem out solutions of the local optimality might be found when avoiding the problem of curse of dimensionality. Unifield adaptive learning approach in the Hopfield Neural Network [3] using the slope adjustment and has adjustment methods for application to economic load dispatch. The methods reduce transient period drastically. The adaptive learning in both methods gives better response compared to fixed 
learning rate. The bias adjustment method gives good response especially in the beginning of the process. Both methods reduced the number of iterations to one half of the traditional Hopfield neural network. When the momentum is introduced to all methods in either input or gain, the number of iterations and the computation time are reduced in the order of magnitude. This promises a great potential of the proposed method for real-time ELD. , Evolutionary programming based algorithm [4] for environmentally-constrained economic dispatch was developed to solve the highly non linear ED problem without restrictions on the shape of fuel cost functions. These applications, however, involved a large number of iterations and were susceptible to the related control parameters. Simple Tabu Search algorithm (STS) [5] introduced by Glover has been successfully applied to a number of integer optimization problems. STS avoids cycling by storing the information of the past from the search. [PSO] Particle swarm optimization technique [6] is a powerful technique to solve combinatorial optimization problems. It minimizes the probability of falling into a local minimum. It has good rule of finding a diversified and intensified neighborhood so that a vast solution space can be explored.

\section{GLOBAL WARMING}

\subsection{Climate Change}

Global warming is the increase in the average temperature of the Earth's near-surface air and oceans since the mid-20th century and its projected continuation. Global surface temperature increased $0.74 \pm 0.18^{\circ} \mathrm{C}\left(1.33 \pm 0.32^{\circ} \mathrm{F}\right)$ between the start and the end of the 20th century. The Intergovernmental Panel on Climate Change (IPCC) concludes that most of the observed temperature increase since the middle of the 20th century was caused by increasing concentrations of greenhouse gases resulting from human activity such as fossil fuel burning and deforestation. These basic conclusions have been endorsed by more than 40 scientific societies and academies of science said that the global surface temperature will probably rise a further 1.1 to $6.4{ }^{\circ} \mathrm{C}(2.0$ to $11.5^{\circ} \mathrm{F}$ ) during the twenty-first century. The uncertainty in this estimate arises from the use of models with differing sensitivity to greenhouse gas concentrations and the use of differing estimates of future greenhouse gas emissions. Some other uncertainties include how warming and related changes will vary from region to region around the globe. Warming is expected to continue beyond 2100 even if emissions stop, because of the large heat capacity of the oceans and the long lifetime of carbon dioxide in the atmosphere. An increase in global temperature will cause sea levels to rise and will change the amount and pattern of precipitation, probably including expansion of subtropical deserts.

\subsection{Green House Gases}

The greenhouse effect is the process by which absorption and emission of infrared radiation by gases in the atmosphere warm a planet's lower atmosphere and surface. Human activity since the Industrial Revolution has increased the amount of greenhouse gases in the atmosphere, leading to increased radioactive forcing from $\mathrm{CO}_{2}$, methane, troposphere ozone, $\mathrm{CFCs}$ and nitrous oxide. Fossil fuel burning has produced about three-quarters of the increase in $\mathrm{CO}_{2}$ from human activity over the past 20 years. Most of the rest is due to land-use change, particularly deforestation. $\mathrm{CO}_{2}$ concentrations are continuing to rise due to burning of fossil fuels and land-use change. The future rate of rise will depend on uncertain economic, sociological, technological, and natural developments. The IPCC Special Report on Emissions Scenarios gives a wide range of future $\mathrm{CO}_{2}$ scenarios, ranging from 541 to 970 ppm by the year 2100 .

\subsection{Oceanic Ecosystems}

Ocean ecosystems' ability to sequester carbon is expected to decline as the oceans warm. This is because warming reduces the nutrient levels of the mesopelagic zone (about 200 to $1000 \mathrm{~m}$ deep), which limits the growth of diatoms in favor of smaller phytoplankton that are poorer biological pumps of carbon.

\subsection{Carbon Dioxide Release from Oceans}

$\mathrm{CO}_{2}$ is reduced by photosynthesis of plants and by dissolving in the oceans reacts to form carbonic acid and bicarbonate and carbonate ions. Cooler water can absorb more $\mathrm{CO}_{2}$. As ocean temperatures rise some of this $\mathrm{CO}_{2}$ will be released. This is one of the main reasons why atmospheric $\mathrm{CO}_{2}$ is lower during an ice age. There is a greater mass of $\mathrm{CO}_{2}$ contained in the oceans than there is in the atmosphere.

\subsection{Mitigation}

Carbon capture and storage (CCS) is an approach to mitigation. Emissions may be sequestered from fossil fuel power plants, or removed during processing in hydrogen production. When used on plants, it is known as storage. Mitigation of global warming is accomplished through reductions in the rate of anthropogenic greenhouse gas release. Models suggest that mitigation can quickly begin to slow global warming, but that temperatures will appreciably decrease only after several centuries.

\subsection{Atmospheric Lifetime}

Aside from water vapor, which has a residence time of about nine days, major greenhouse gases are well-mixed, and take many years to leave the atmosphere. Although it is not easy to know with precision how long it takes greenhouse gases to leave the atmosphere, there are estimates for the principal greenhouse gases. Jacob (1999) defines the lifetime $\tau$ of an atmospheric species. Mathematically $\tau$ can be defined as the ratio of the mass $m$ (in $\mathrm{kg}$ ) of $\mathrm{X}$ in the box to its removal rate, which is the sum of the flow of $\mathrm{X}$ out of the box $\left(F_{\text {out }}\right)$, chemical loss of $\mathrm{X}(L)$, and deposition of $\mathrm{X}(D)$ (all in $\mathrm{kg} / \mathrm{sec})$ :

$$
\mathrm{\tau}=\frac{m}{F_{\text {out }}+L+D}
$$

The atmospheric lifetime of a species therefore measures the time required to restore equilibrium following an increase in its concentration in the atmosphere. Individual atoms or molecules may be lost or deposited to sinks such as the soil, the oceans and other waters, or vegetation and other biological systems, reducing the excess to background concentrations. The average time taken to achieve this is the mean lifetime. The atmospheric lifetime of $\mathrm{CO}_{2}$ is often incorrectly stated to be only a few years because that is the average time for any $\mathrm{CO}_{2}$ molecule to stay in the atmosphere before being removed by mixing into the ocean, photosynthesis and other processes.

\section{PROBLEM FORMULATION}

The objective of solving the economic dispatch problem in electric power system is to determine the generation levels for all 
on-line units which minimize the emission level of the system, while satisfying a set of constraints. It can be formulated as follows:

\subsection{Emission Equation}

The Emission equation of a generating unit is usually described by a quadratic function of power output $\mathrm{P} i$ as:

$$
E_{i}\left(P_{i}\right)=\mathrm{d}_{\mathrm{i}} \mathrm{P}_{\mathrm{i}}^{2}+\mathrm{e}_{\mathrm{i}} \mathrm{P}_{\mathrm{i}}+\mathrm{f}_{\mathrm{i}} \mathrm{kg} / \mathrm{hr}
$$

Where

$$
\mathrm{d}_{\mathrm{i}}, \mathrm{e}_{\mathrm{i}} \text { and } \mathrm{f}_{\mathrm{i}} \text { are the emission co-efficient of unit } \mathrm{i}
$$

\subsection{Power Balance Constraints}

The total generation must supply the demand

Where

$$
\Sigma\left(\mathrm{P}_{\mathrm{i}}\right)=\mathrm{P}_{\mathrm{D}}
$$

$P_{D}$ is the load demand

\subsection{Generator Limit Constraints}

The power generation of unit ' $n$ ' should be between its minimum and maximum limits.

$$
\mathrm{P}_{\mathrm{n}} \min <\mathrm{P}_{\mathrm{n}}<\mathrm{P}_{\mathrm{n}} \max
$$

Where

$P_{i}$ min is the minimum generation limit of unit $i$

$\mathrm{P}_{\mathrm{i}}$ max is the maximum generation limit of unit $\mathrm{i}$

\section{PARTICLE SWARM OPTIMISATION}

PSO simulates the behaviors of bird flocking. Suppose the following scenario: a group of birds are randomly searching food in an area. There is only one piece of food in the area being searched. All the birds do not know where the food is. But they know how far the food is in each iteration. So what's the best strategy to find the food? The effective one is to follow the bird, which is nearest to the food. PSO learned from the scenario and used it to solve the optimization problems. In PSO, each single solution is a "bird" in the search space. We call it "particle". All of particles have fitness values, which are evaluated by the fitness function to be optimized, and have velocities, which direct the flying of the particles. The particles fly through the problem space by following the current optimum particles.PSO is initialized with a group of random particles (solutions) and then searches for optima by updating generations. In every iteration, each particle is updated by following two "best" values. The first one is the best solution (fitness) it has achieved so far. (The fitness value is also stored.)This value is called pbest. Another "best" value that is tracked by the particle swarm optimizer is the best value, obtained so far by any particle in the population. This best value is a global best and called g-best. When a particle takes part of the population as its topological neighbors, the best value is a local best and is called p-best. After finding the two best values, the particle updates its velocity and positions with following equation (4) \& (5)

$$
\begin{aligned}
\mathrm{V}_{\mathrm{i}}(\mathrm{u}+1)=\mathrm{w} * \mathrm{~V}_{\mathrm{i}}(\mathrm{u})+\mathrm{C} 1 * \text { rand }() *\left(\text { pbest }_{\mathrm{i}}-\mathrm{P}_{\mathrm{i}}(\mathrm{u})\right) \\
+\mathrm{C} 2 * \text { rand }() *\left(\mathrm{~g}_{\text {besti }}-\mathrm{P}_{\mathrm{i}}(\mathrm{u})\right)
\end{aligned}
$$

$\mathrm{P}_{\mathrm{i}}(\mathrm{u}+1)=\mathrm{P}_{\mathrm{i}}(\mathrm{u})+\mathrm{V}_{\mathrm{i}}(\mathrm{u}+1)$

In the above equation,

- $\operatorname{rand}()^{*}\left(\right.$ pbest $\left._{i}-P_{i}(u)\right)$ is called particle memory influence.

- rand ()$^{*}\left(\right.$ gbest $\left._{\mathrm{i}}-\mathrm{P}_{\mathrm{i}}(\mathrm{u})\right)$ is called swarm influence.

- $\mathrm{V}_{\mathrm{i}}(\mathrm{u})$ which is the velocity of $\mathrm{i}^{\text {th }}$ particle at iteration ' $\mathrm{u}$ ' must lie in the range $\mathrm{V}_{\min } \leq \mathrm{Vi}(\mathrm{u}) \leq \mathrm{V}_{\max }$

- The parameter $V_{\max }$ determines the resolution, or fitness, with which regions are to be searched between the present position and the target position

- If $\mathrm{V}_{\max }$ is too high, particles may fly past good solutions.

- If $\mathrm{V}_{\min }$ is too small, particles may not explore sufficiently beyond local solutions.

- In many experiences with PSO, $\mathrm{V}_{\max }$ was often set at $10-20 \%$ of the dynamic range on each dimension.

- The constants C1and C2 pull each particle towards $\mathrm{P}_{\text {best }}$ and $g_{\text {best }}$ positions.

- Low values allow particles to roam far from the target regions before being tugged back. On the other hand, high values result in abrupt movement towards, or past, target regions.

- The acceleration constants $\mathrm{C} 1$ and $\mathrm{C} 2$ are often set to be 2.0 according to past experiences.

- Suitable selection of inertia weight ' $\omega$ ' provides a balance between global and local explorations, thus requiring less iteration on average to find a sufficiently optimal solution.

- In general, the inertia weight $w$ is set according to the following equation,

$$
\mathrm{W}=\mathrm{W}_{\max }-\left[\frac{W \max -W \min }{I T E R \max }\right] \mathrm{X} \text { ITER }
$$

Where

$\mathrm{w}-$ is the inertia weighting factor

Wmax - maximum value of weighting factor

Wmin - minimum value of weighting factor

ITERmax - maximum number of iterations

ITER - current number of iteration

\section{EXPERIMENTS AND RESULTS}

The power system economic dispatch problem based on the concept of Particle Swarm Optimization technique has been tested on 3-generator system and 6-generator system. Multiple generator limits and total emission level of the system is simulated in order to evaluate the correctness as well as accuracy of this method. The first test system consists of 3-generating units with various demand of 200-400 MW. The emission coefficient and generating limits of the 3-generator system are shown in table (I).The second test system consists of 6-generating units with various demand of 500-1100 MW. The emission coefficient and generating limits of the 6-generator system are shown in table (II). 


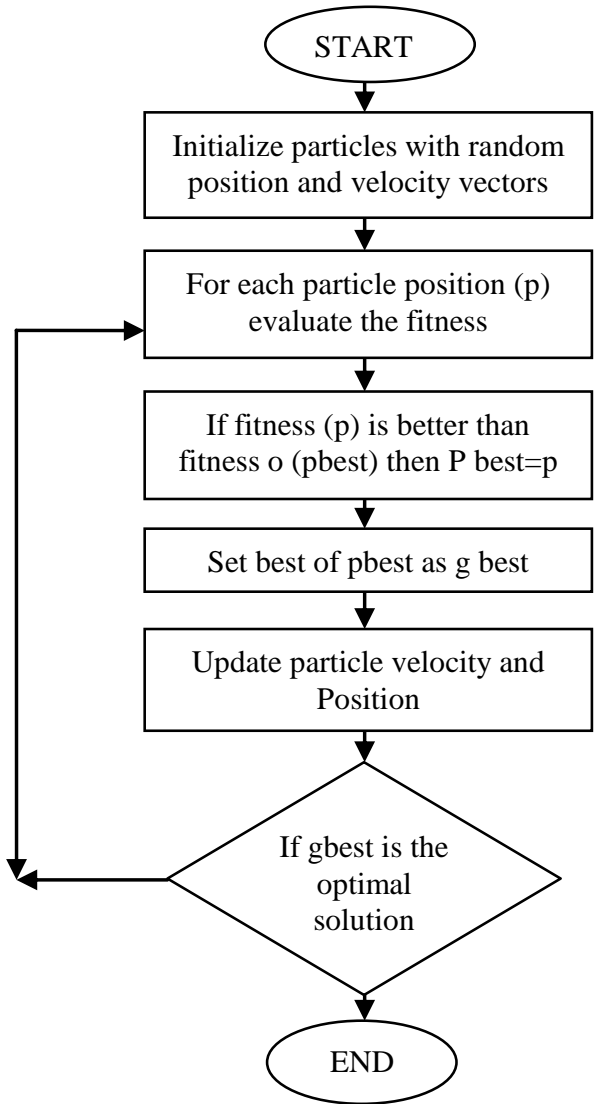

Fig1. Flow chart for Particle Swarm Optimization application to Economic load dispatch

Table 1. Emission coefficients and power limits for three generator system

\begin{tabular}{|c|c|c|c|c|c|}
\hline Generator & $\mathbf{d}_{\mathbf{i}}$ & $\mathbf{e}_{\mathbf{i}}$ & $\mathbf{f}_{\mathbf{i}}$ & $\mathbf{P}_{\min }$ & $\mathbf{P}_{\max }$ \\
\hline $\mathbf{1}$ & 0.0126 & $\begin{array}{c}- \\
1.355\end{array}$ & 22.983 & 20 & 200 \\
\hline $\mathbf{2}$ & 0.01375 & $\begin{array}{c}- \\
1.249\end{array}$ & 137.370 & 15 & 150 \\
\hline $\mathbf{3}$ & 0.00765 & $\begin{array}{r}- \\
0.805\end{array}$ & 363.704 & 18 & 180 \\
\hline
\end{tabular}

Table 2. Emission coefficients and power limits for six generator system

\section{SIMULATION TEST RESULTS}

The Particle swarm optimization technique is used to solve the

\begin{tabular}{|c|c|c|c|c|c|}
\hline Generator & $\mathbf{d}_{\mathbf{i}}$ & $\mathbf{e}_{\mathbf{i}}$ & $\mathbf{f}_{\mathbf{i}}$ & $\begin{array}{c}\mathbf{P} \\
\mathbf{m i n}\end{array}$ & $\begin{array}{c}\mathbf{P} \\
\mathbf{M a x}\end{array}$ \\
\hline 1 & 0.0042 & 0.3300 & 13.86 & 10 & 125 \\
\hline 2 & 0.0042 & 0.3300 & 13.86 & 10 & 150 \\
\hline 3 & 0.0068 & -0.5455 & 40.26 & 35 & 225 \\
\hline 4 & 0.0068 & -0.5455 & 40.26 & 35 & 210 \\
\hline 5 & 0.0046 & -0.5112 & 42.92 & 130 & 325 \\
\hline 6 & 0.0046 & -0.5112 & 42.96 & 125 & 315 \\
\hline
\end{tabular}

Economic Dispatch problem for 3-generator test system and 6generator test system. The simulation is carried out using c++ software. The emission level of system is minimized. The computational results of table (III) and table (IV) consists of three generator test system and six generator test system respectively, shows that in PSA technique the emission level is less than conventional methods. It concludes that the emission level is minimum in particle swarm optimization technique compared to other techniques with considering emission equations, power balance constraints and generator limit constraints. In comparison of the test system, it can be seen that when a large scale problem, PSO can clearly obtain solution better than other methods and converges to near global minimum with less search account

Table 3. Comparison of particle swarm optimization solution for economic dispatch emission value under various load conditions for three generator system

\begin{tabular}{|c|c|c|}
\hline \multirow{2}{*}{$\begin{array}{c}\text { Generation } \\
\text { MW }\end{array}$} & \multicolumn{2}{|c|}{ Total Emission (Kg/hr) } \\
\cline { 2 - 3 } & $\begin{array}{c}\text { Proposed } \\
\text { Method }\end{array}$ & $\begin{array}{c}\text { Conventional } \\
\text { Method }\end{array}$ \\
\hline 200 & $\mathbf{5 2 1 . 0 8 1 5}$ & 529.26 \\
\hline 250 & $\mathbf{5 8 3 . 7 9 4 2}$ & 597.499 \\
\hline 300 & $\mathbf{6 7 9 . 6 3 7 8}$ & 684.826 \\
\hline 350 & $\mathbf{7 6 2 . 1 8 7 8}$ & 791.24 \\
\hline 400 & $\mathbf{8 7 8 . 5 7 6 5}$ & 916.742 \\
\hline
\end{tabular}

Table 4. Comparison of particle swarm optimization solution for economic dispatch emission value under various load conditions for six generator system

\begin{tabular}{|c|c|c|}
\hline \multirow{2}{*}{ Generation MW } & \multicolumn{2}{|c|}{ Total Emission (Kg/hr) } \\
\cline { 2 - 3 } & Proposed Method & $\begin{array}{c}\text { Conventional } \\
\text { Method }\end{array}$ \\
\hline 500 & $\mathbf{2 5 1 . 1 8 2 2}$ & 261.634 \\
\hline 600 & $\mathbf{3 2 9 . 3 5 9 9}$ & 338.992 \\
\hline 700 & $\mathbf{4 2 8 . 5 0 9 5}$ & 434.38 \\
\hline 800 & $\mathbf{5 4 0 . 2 8 0 1}$ & 547.796 \\
\hline 900 & $\mathbf{6 5 0 . 4 2 4 0}$ & 679.24 \\
\hline 1000 & $\mathbf{7 9 3 . 7 6 4 0}$ & 828.72 \\
\hline 1100 & $\mathbf{9 5 3 . 3 3 1 1}$ & 996.224 \\
\hline
\end{tabular}




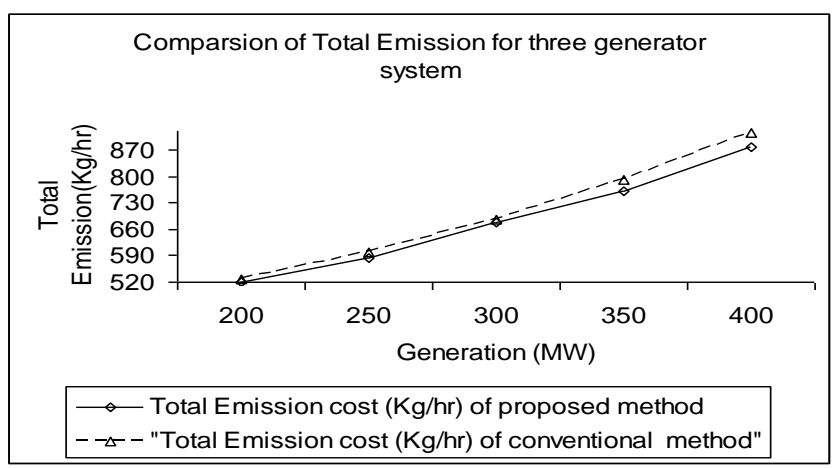

Fig 2 comparison of Total Emission for three generator system

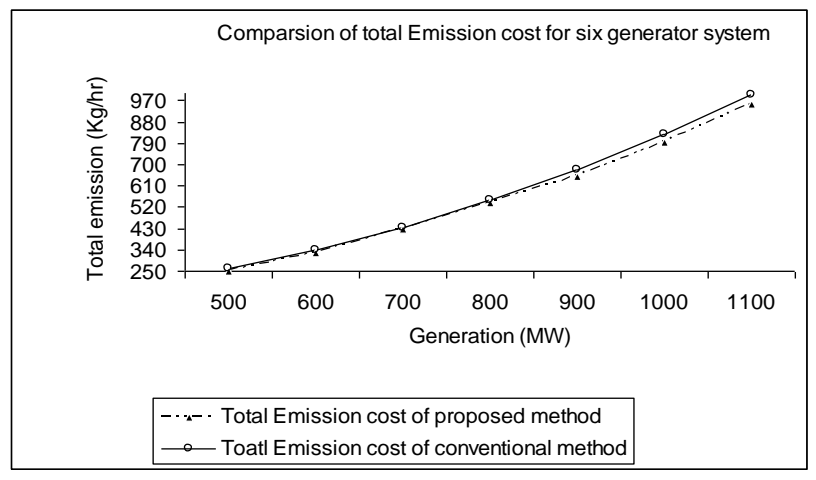

Fig 3 comparison of Total Emission cost for six generator system

\section{SUMMARY AND CONCLUSION}

Particle Swarm Optimization Technique has been applied for optimizing the economic dispatch problem for minimizing the emission level of the thermal power plants. It is seen from the simulation results that the proposed method reduces the global warming by minimizing the concentration of $\mathrm{Co}_{2}$ in fossil burning of fuels. The quality of the solution shows that the Particle Swarm Optimization Technique offers a promising viable approach for solves the economic thermal power dispatch problem. The solution is analytic in nature with high accuracy involving less computational time. It is used for any online applications becomes boundless. The numerical results have shown the performance and applicability of the proposed method. This technique is very well defined and the solution accuracy is excellent in conformity with the conventional techniques.
The Particle Swarm Optimization Technique (PSO) can converge to near global minimum with less search account. It is high efficiency than other methods. Thus, it obtains the solution with high accuracy.

\section{ACKNOWLEDGMENTS}

The authors gratefully acknowledge the authorities of St.Joseph college of Engineering and Technology, Dar Es Salaam for the facilities offered to carry out this work.

\section{REFERENCES}

[1] C.E. Lin and G.L. Viviani, "Hierarchical economic dispatch for piecewise quadratic cost functions," IEEE Trans. Power Apparatus Syst., vol. PAS-103, pp. 1170-1175, June 1984.

[2] Z.X. Liang and J.D. Glover, "Azoom feature for a dynamic programming solution to economic dispatch including transmission losses," Trans. Power Syst., vol. 7, pp. 544550, May 1992.

[3] K. Y. Lee, A. S. Yome, and J. H. Park, "Adaptive Hopfield networks for economic load dispatch," IEEE Trans. Power Syst., vol. 13, pp. 519-526, May 1998..

[4] K. P. Wong and J. Yuryevich, "Evolutionary-programmingbased algorithm for environmentally-constrained economic dispatch," IEEE Trans. Power Syst., vol. 13, pp. 301-306, May 1998.

[5] A.H. Mantawy, Y.L Abdel-Magid, and S.Z. Selim,"A new genetic-based simple tabu search algorithm for unit commitment problem," Electr.power syst. Res. 49,pp. 71$78,1999$.

[6] Konash, O.El-Sharakawi, M, "Economic Dispatch using Particle Swarm Optimization for combined cycle generators" Power Systems Conference and Exposition, 2009. PSCE IEEE/PES Volume, Issue,15-18 March 2009 Page(s):1-9.

[7] K.P.Wong and C.C.Fung, Simulated Annealing based Economic Load Dispatch, IEEE proceedings on Generation, Transmission and Distribution-C, Vol.140,No.6, Nov 1993, pp 509-513.

[8] Leandro dos Santos Coelho and Chu-Sheng Lee Solving economic load dispatch problems in power systems using chaotic and Gaussian particle swarm optimization approaches" International Journal of Electrical Power \& Energy Systems, Volume 30, Issue 5, June 2008, Pages297307. 